\title{
Pengaruh Pelatihan Berprilaku Caring Terhadap Kemampuan Caring Mahasiswa Praktek Profesi Fakultas Keperawatan Unand di RSUP Dr.M.Djamil Padang
}

\author{
Reni Prima Gusty \\ email : reni.rafie@gmail.com
}

\begin{abstract}
Caring nurse behavior will be guarantee quality care, because Caring is the essence of nursing between nurses means responsive to the clients. Therefore Unand nursing faculty seeks caring training to make students better prepared to provide quality nursing care when the practice of the profession and to produce graduates who are ready kerja.Penelitian examines the effect of training on kemampun caring Caring Professions School of Nursing Students Practice Unand. This type of research experimentation Quasi one-group pretest- posttest design. Students study subjects practice the profession in Dr M Djamil Padang Hospital numbered 22 peoples and spread across nine rooms are neurologi , pulmonary, male internal, female internal, high care unit, female surgical, male surgical , trauma centere and recovery room. Instruments is queationer that measure eight capability caring consist of hear clients with caring attentive, giving a sense of security, a touch, build trusting relationships, responsibility, information, sensitive to the client, and respecting the client. Students were trained for 2 days with bedside teaching methods. Analysis of the data processed using Marginal homogenity test to see the effect of training on kemampun caring Caring Professions School of Nursing Students Practice Unand. The results showed that there is an increased ability to behave in the caring professions students of the Faculty of Nursing Unand practice after the training given to the value of $p=0.000$. Using suggestions caring approach to training in small groups more able to improve psychomotor skills of students in the practice of land. And can be used by professionals as part of main graduation loaded
\end{abstract}

Keywords : Training, Behavior, Caring

\begin{abstract}
Abstrak
Perilaku Caring perawat menjadi jaminan akan layanan perawatan bermutu, karena Caring merupakan intisari keperawatan yang mengandung arti responsive antara perawat dengan klien. Oleh sebab itu fakultas keperawatan Unand berupaya melakukan pelatihan caring untuk membuat mahasiswa lebih siap memberikan pelayanan keperawatan yang berkualitas ketika praktek profesi dan menghasilkan lulusan yang siap kerja.Penelitian bertujuan melihat Pengaruh Pelatihan Caring terhadap kemampun caring Mahasiswa Praktek Profesi Fakultas Keperawatan Unand. Jenis penelitian Quasi Esperimen pretest posttest one group design. Subjek penelitian Mahasiswa praktek profesi di RSUP Dr M Djamil Padang berjumlah 22 orang dan tersebar di Sembilan ruang perawatan yaitu saraf, paru, interna pria, interna wanita, high care unit (HCU), bedah wanita, bedah pria, trauma centere dan ruang pemulihan. Instrumen menggunakan queationer dengan melihat 8 kemampuan caring yaitu mendengar klien dengan penuh perhatian, memberi rasa aman,memberi sentuhan, membina hubungan saling percaya,tanggung jawab,pemberian informasi, sensitive terhadap klien, dan menghormati klien. Mahasiswa diberi pelatihan selama 2 hari dengan metode bedside teaching. Analisa data diolah dengan menggunakan uji Marginal Homogenity untuk melihat Pengaruh Pelatihan Caring terhadap kemampun caring Mahasiswa Praktek Profesi Fakultas Keperawatan Unand. Hasil penelitian menunjukkan bahwa ada peningkatan kemampuan berprilaku caring pada mahasiswa praktek profesi Fakultas Keperawatan Unand setelah diberi pelatihan dengan nilai $\mathrm{p}=0,000$. Saran Menggunakan pendekatan pelatihan caring dalam kelompok kecil lebih bisa meningkatkan kemampuan psikomotor mahasiswa di lahan praktek. Dan dapat digunakan oleh bagian profesi sebagai sarat kelulusan utama

kata kunci : Pelatihan,Prilaku, Caring

Era globalisasi yang akan kita hadapi dibidang kesehatan menuntut agar pelayanan kesehatan yang diberikan ke masyarakat semakin meningkat dan mampu bersaing

dengan rumah sakit yang berada didalam maupun luar negeri. Pencapaian dapat dilakukan dengan melakukan upaya peningkatan mutu pelayanan kesehatan di
\end{abstract}


rumah sakit. Salah satu faktor dominan adalah sumber daya manusia (Depkes, 2002). Keperawatan sangat mempengaruhi kualitas pelayanan kesehatan, bahkan menjadi salah satu faktor penentu citra institusi pelayanan kesehatan (rumah sakit) di mata masyarakat. Hal ini terjadi karena keperawatan merupakan kelompok profesi dengan jumlah terbanyak, paling depan dan terdekat dengan penderitaan orang lain, kesakitan, kesengsaraan yang dialami masyarakat.

Perilaku Caring (kepedulian) perawat menjadi jaminan akan layanan perawatan bermutu. Caring adalah istilah yang harus identik dengan keperawatan. Sebagian besar siswa memilih untuk masuk keperawatan karena mereka memiliki keinginan untuk peduli dengan orang lain. Sementara beberapa

perawat mungkin terampil, namun menjadi perawat yang sesungguhnya dapat dinilai dari prilaku caring yang mereka berikan ke klien (Iggulden Helen ,2009). Caring merupakan intisari dari keperawatan yang mengandung arti responsive antara perawat dengan klien (Asmadi,2005). Fakultas Keperawatan Unand sebagai institusi pendidikan yang ikut bertanggung jawab untuk menghasilkan lulusan sarjana keperawatan yang memiliki prilaku caring. Ilmu keperawatan menyakini bahwa keperawatan merupakan pelayanan professional yang bersifat humanistic (berlandaskan kemanusiaan, nilai dan moral manusia), holistik (melihat manusi dan lingkungan secara utuh berdasarkan biopsiko-sosial-spiritual) dan caring (kepedulian) yang merupakan dasar dalam praktik keperawatan (Nursalam,2007). Dalam membantu klien mencapai potensi kesehatan sepenuhnya perawat harus mempunyai suatu pendekatan yang menyeluruh. Pendekatan keperawatan komprehensif, yaitu pemberian asuhan keperawatan secara bio, psiko, sosio, spiritual merupakan pendekatan yang digunakan oleh perawat. Pendekatan ini menggunakan konsep dan ilmu yang terkait dengan keperawatan, salah satunya adalah caring (Watson, 2003).

Rosalina (2008) menyatakan bahwa kenyataan yang ada dalam layanan jasa kesehatan pada klien belum memuaskan. Hal ini terbukti dengan masih banyak keluhan klien dan keluarganya terhadap sikap dan perilaku perawat dalam memberikan layanan kesehatan. Ketidakpuasan yang disampaikan oleh klien antara lain adalah perawat yang kurang ramah dan kurang tanggap terhadap keluhan klien dan keluarganya, padahal 90\% layanan kesehatan di rumah sakit terhadap klien adalah layanan keperawatan. Disinilah perawat harus memahami dan menyadari perannya dalam memberikan perawatan.

Kepuasan klien juga erat hubungannya dengan asuhan keperawatan yang dilakukan oleh perawat dengan perilaku caring. Anjaswarni (2002) pada hasil penelitiannya menegaskan bahwa didapatkan secara keseluruhan rata-rata tingkat kepuasan klien tinggi terhadap perilaku caring oleh perawat di RSUD Dr. Saiful Anwar Malang. Berdasarkan pencapaian rata-rata tingkat kepuasan ini dapat diketahui bahwa pencapaian tingkat kepuasan klien terhadap perilaku caring adalah $82,25 \%$ yang berarti klien cenderung merasa puas. Hasil penelitian Ismar,A tahun 2002 di Rumah Sakit Muhammad Hoesin Palembang menunjukkan hampir separoh perawat yang diteliti dinilai tidak caring $(48,3 \%)$ dan sebagian besar klien tidak puas terhadap perilaku caring perawat $(79,2 \%)$. Dari data tersebut ada perawat yang sudah mempunyai perilaku caring dan masih ada perawat yang belum berperilaku caring sehingga mempengaruhi kualitas asuhan keperawatan yang selanjutnya berdampak terhadap kepuasan klien akan pelayanan rumah sakit secara keseluruhan.

Berdasarkan hasil wawancara pada bulan september 2012 dengan 15 orang klien yang diambil masing -masing 5 orang secara 
acak dari ruang rawat inap bedah dan non bedah di Rumah Sakit Umum Pusat Dr. M Djamil Padang menyatakan bahwa 10 orang mengeluh perawat dan mahasiswa keperawatan yang ada diruangan kurang ramah \& tersenyum, cendrung bertanya hanya untuk mendapatkan data fisik, kurang perhatian dalam memberikan asuhan keperawatan dan sering tidak peduli terhadap klien, 5 orang klien mengatakan cukup ramah dan baik terhadap klien. Berdasarkan wawancara dengan 5 orang perawat dari RSUP Dr. M Djamil Padang mengatakan bahwa rumah sakit Semenjak September 2012 menerapkan aturan pada seluruh tenaga kesehatan rumah sakit untuk selalu bersifat ramah dan tersenyum ketika melayani pasien.

Berdasarkan fenomena diatas peneliti merasa perlu dilakukan pelatihan berprilaku caring kepada mahasiswa keperawatan agar konsep yang telah dipelajari dapat menjadi diaplikasikan nyata ketika memasuki praktik profesi pertama kali. Pelatihan menjadi penting sesuai dengan yang diungkapkan Good (1973) dalam Riche Cyntia Johan, dkk., 2010 pelatihan adalah suatu proses membantu orang lain dalam memperoleh keterampilan dan pengetahuan. Sementara Michael J. Jucius dalam Moekijat (1991:2) menjelaskan istilah latihan untuk menunjukkan setiap proses untuk mengembangkan bakat, keterampilan, dan kemampuan pegawai guna menyelesaikan pekerjaan-pekerjaan tertentu

\section{METODE}

Jenis penelitian Quasi eksperimental dengan rancangan penelitian pre test post test one group design. Penelitian ini menggunakan pendekatan cross sectional dimana observasi atau pengumpulan data sekaligus pada suatu saat. Intervensi yang diberikan yakni pelatihan berprilaku caring selama 2 hari, dan kemudian penilaian post test dilakukan setelah 3 hari pelatihan.
Penelitian ini dilakukan di RSUP Dr. M Djamil Padang di ruang IRNA Bedah dan Non Bedah RSUP Dr M Djamil Padang yang meliputi ruang saraf,paru,interna,bedah

Populasi yang diambil dalam penelitian ini adalah mahasiswa fakultas keperawatan unand yang melakukan praktek dengan jumlah 22 orang. Sampel adalah semua mahasiswa yang praktek profesi berjumlah 22 orang. Alat ukur yang dipakai pada penelitian ini adalah kuesioner dengan butir pertanyaan sebanyak 40 buah

Untuk melihat pengaruh pelatihan terhadap kemamapuan caring mahasiswa dengan menggunakan uji Marginal Homogeneity. Nilai kemaknaan yang digunakan adalah 955 atau $\mathrm{p}=0,05$. Jika $\mathrm{p} \leq$ 0,05 berarti ada pengaruh pelatihan berprilaku caring terhadap peningkatan kemampuan mahasiswa praktek profesi fakultas keperawatan Unand di RSUP Dr M Djamil Padang. Jika hasil uji statistik nilai $\mathrm{p}$ $>0,05$ secara statistik disebut diartikan tidak terdapat pengaruh pelatihan berprilaku caring terhadap kemampuan mahasiswa praktek profesi fakultas keperawatan Unand di RSUP Dr M Djamil Padang.

\section{HASIL DAN PEMBAHASAN \\ A. Gambaran Umum Penelitian}

Penelitian ini di lakukan pada mahasiswa praktek profesi di ruangan IRNA Bedah dan IRNA Non Bedah RSUP Dr. M Djamil Padang. Penelitian ini dimulai dengan pengumpulan data awal (pretest) pada tanggal 13-1 6 Desember 2012 dengan jumlah responden 22 orang mahasiswa profesi Fakultas Keperawatan Unand. Selanjutnya pada tanggal 13-14 desember 2012 pelatihan dilakukan pada ruang saraf paru,dan ruang penyakit dalam sedangkan tanggal 17-18 desember 2012 dilakukan pelatihan di ruang bedah. Pengambilan data posttest untuk saraf, paru dan interna dilakukan 19-21 desember 2012 sedangkan di bedah pengambilan data posttest di ruang bedah tanggal 22-24 desember 2012. Dalam penelitian ini responden berasal dari 9 ruangan rawat inap, dengan perincian 3 orang dari saraf, 2 orang dari paru, 2 orang dari 
$\mathrm{HCU}, 3$ orang dari interna pria,3 orang dari interna wanita, 2 orang dari Trauma Center, 2 orang dari bedah pria, 2orang dari bedah wanita, dan 3 orang dari ruang pemulihan (RR). kesemua responden dalam penelitian ini ditemukan berjenis kelamin perempuan.

\section{B. Karakteristik Responden}

Tabel 1. Distribusi frekuensi karakteristik Mahasiswa Praktek Profesi Fakultas Keperawatan Unand di Ruang Rawat Inap RSUP Dr M. Djamil Padang Bulan Desember Tahun 2012

\begin{tabular}{|c|c|c|c|c|}
\hline No & $\begin{array}{c}\text { Karakteri } \\
\text { stik }\end{array}$ & Kriteria & Frekuensi & $\begin{array}{l}\text { Perse } \\
\text { ntase }\end{array}$ \\
\hline \multirow[t]{3}{*}{1} & Jenis & Perempuan & 20 & 91 \\
\hline & kelamin & Laki-laki & 2 & 9 \\
\hline & \multicolumn{2}{|c|}{ Total } & 22 & 100 \\
\hline \multirow[t]{4}{*}{1} & Latar & SLTA & 13 & 60 \\
\hline & belakang & DIII Kep & 9 & 40 \\
\hline & Pendidik & & & \\
\hline & \multicolumn{2}{|c|}{ Total } & 22 & 100 \\
\hline \multirow[t]{4}{*}{2} & Riwayatk & Belum & 17 & 77,3 \\
\hline & Pekerjaa & bekerja & 5 & 23,7 \\
\hline & $\mathrm{n}$ & $\begin{array}{l}\text { Sudah } \\
\text { bekerja }\end{array}$ & & \\
\hline & \multicolumn{2}{|c|}{ Total } & 22 & 100 \\
\hline
\end{tabular}

Berdasarkan tabel 1 diatas tentang karakteristik dari 22 orang responden, jika dilihat dari karakteristik jenis kelami sebagian besar berjenis kelamin perempuan 20 orang (91\%), lebih dari separoh responden berlatar belakang pendidikan lulusan SLTA 13 orang (60\%) dan belum pernah bekerja sebanya $17(77,3 \%)$.

\section{Hasil Analisa Data}

\section{Analisa Univariat}

Tabel 2. Distribusi Frekuensi Komponen Kemampuan Caring Mahasiswa Praktek

Profesi Fakultas Keperawatan Unand Sebelum dan sesudah diberikan Pelatihan Berprilaku Caring di RSUP Dr.M Djamil Padang Desember 2012

\begin{tabular}{|c|c|c|c|c|}
\hline $\begin{array}{c}\text { Kemampuan caring } \\
\text { mahasiswa }\end{array}$ & \multicolumn{2}{|c|}{ sebelum } & \multicolumn{2}{|c|}{ Sesudah } \\
\hline $\begin{array}{l}\text { 1. Mendengar } \\
\text { klien }\end{array}$ & $\mathrm{f}$ & $\%$ & $\mathrm{f}$ & $\%$ \\
\hline Kurang & 1 & 4,5 & 0 & 0 \\
\hline Cukup & 17 & 77,3 & 0 & 0 \\
\hline Baik & 4 & 18,2 & 7 & 31,8 \\
\hline Sangat baik & 0 & 0 & 15 & 68,2 \\
\hline total & 22 & 100 & 22 & 100 \\
\hline $\begin{array}{ll}\text { 2. } & \text { Memberikan } \\
& \text { rasa aman dan } \\
& \text { nyaman }\end{array}$ & & & & \\
\hline Kurang & 5 & 22,7 & 0 & 0 \\
\hline Cukup & 17 & 77,3 & 2 & 10 \\
\hline Baik & 0 & 0 & 10 & 45,5 \\
\hline Sangat baik & 0 & 0 & 10 & 45,5 \\
\hline total & 22 & 100 & 22 & 100 \\
\hline $\begin{array}{l}\text { 3. Memberikan } \\
\text { sentuhan }\end{array}$ & & & & \\
\hline Kurang & 7 & 31,9 & 0 & 0 \\
\hline Cukup & 12 & 54,5 & 0 & 0 \\
\hline Baik & 3 & 13,6 & 6 & 27,3 \\
\hline Sangat baik & 0 & 0 & 16 & 72,7 \\
\hline total & 22 & 100 & 22 & 100 \\
\hline
\end{tabular}




\begin{tabular}{|c|c|c|c|c|}
\hline $\begin{array}{l}\text { Kemampuan caring } \\
\text { mahasiswa }\end{array}$ & \multicolumn{2}{|c|}{ sebelum } & \multicolumn{2}{|c|}{ Sesudah } \\
\hline $\begin{array}{l}\text { 4.Membina } \\
\text { hubungan saling } \\
\text { percaya }\end{array}$ & $\mathrm{f}$ & $\%$ & $\mathrm{f}$ & $\%$ \\
\hline Kurang & 5 & 22,7 & 0 & 0 \\
\hline Cukup & 15 & 68,2 & 2 & 9,1 \\
\hline Baik & 2 & 9,1 & 8 & 36,4 \\
\hline Sangat baik & 0 & 0 & 12 & 54,5 \\
\hline total & 22 & 100 & 22 & 100 \\
\hline $\begin{array}{l}\text { 1. Tanggung } \\
\text { jawab }\end{array}$ & & & & \\
\hline Kurang & 5 & 22,7 & 0 & 0 \\
\hline Cukup & 13 & 59,1 & 0 & 0 \\
\hline Baik & 4 & 18,2 & 2 & 9,1 \\
\hline Sangat baik & 0 & 0 & 20 & 90,9 \\
\hline total & 22 & 100 & 22 & 100 \\
\hline $\begin{array}{ll}\text { 2. } & \begin{array}{l}\text { Memberikan } \\
\text { informasi }\end{array} \\
\end{array}$ & & & & \\
\hline Kurang & 6 & 27,3 & 0 & 0 \\
\hline Cukup & 15 & 68,2 & 2 & 10 \\
\hline Baik & 1 & 4,5 & 10 & 45 \\
\hline Sangat baik & 0 & 0 & 10 & 45 \\
\hline total & 22 & 100 & 22 & 100 \\
\hline $\begin{array}{ll}\text { 3. } & \text { Sensitive } \\
\text { terhadap klien }\end{array}$ & & & & \\
\hline Kurang & 5 & 22,7 & 0 & 0 \\
\hline Cukup & 15 & 68,2 & 2 & 10 \\
\hline Baik & 2 & 9,1 & 10 & 45 \\
\hline Sangat baik & 0 & 0 & 10 & 45 \\
\hline total & 22 & 100 & 22 & 100 \\
\hline $\begin{array}{l}\text { 4. Menghormati } \\
\text { klien }\end{array}$ & & & & \\
\hline Kurang & 2 & 9,1 & 0 & 0 \\
\hline
\end{tabular}

\begin{tabular}{|c|c|c|c|c|}
\hline Cukup & 15 & 68,2 & 0 & 0 \\
\hline Baik & 5 & 22,7 & 5 & 22,7 \\
\hline Sangat baik & 0 & 0 & 17 & 77,3 \\
\hline total & $\mathbf{2 2}$ & $\mathbf{1 0 0}$ & $\mathbf{2 2}$ & $\mathbf{1 0 0}$ \\
\hline
\end{tabular}

Berdasarkan tabel 2 didapatkan bahwa kemampuan caring mahasiswa profesi fakultas keperawatan unand sebelum diberikan pelatihan berprilaku caring menggambarkan lebih dari separoh kemampuan berprilaku caring berada direntang cukup. Sedangkan sesudah diberi pelatihan kemampuan mahasiswa sebagian besr berada di kemampuan sangat baik serta tidak ada mahasiswa yang menunjukkan kemampuan kurang.

Tabel3. Distribusi Frekuensi Kemampuan Caring Mahasiswa Praktek Profesi Fakultas Keperawatan Unand Sebelum dan sesudah diberikan Pelatihan Berprilaku Caring di RSUP Dr.M Djamil Padang Desember 2012

\begin{tabular}{|c|c|c|c|c|}
\hline \multirow{2}{*}{$\begin{array}{c}\text { Kemampuan } \\
\text { caring } \\
\text { mahasiswa }\end{array}$} & \multicolumn{2}{|c|}{ sebelum } & \multicolumn{2}{c|}{ Sesudah } \\
\cline { 2 - 5 } & f & $\%$ & f & \% \\
\hline Kurang & 6 & 27,3 & 0 & 0 \\
\hline Cukup & 13 & 59,1 & 0 & 0 \\
\hline Baik & 3 & 13,6 & 7 & 31,8 \\
\hline Sangat baik & 0 & 0 & 15 & 68,2 \\
\hline total & $\mathbf{2 2}$ & $\mathbf{1 0 0}$ & $\mathbf{2 2}$ & $\mathbf{1 0 0}$ \\
\hline
\end{tabular}

Dari tabel diatas menggambarkan bahwa lebih dari separoh atau 13 orang $(59,1 \%)$ mahasiswa memiliki kemampuan caring cukup sebelum diberi pelatihan. Namun setelah diberi pelatihan Caring sebagian besar mahasiswa 
memiliki kemampuan caring sangat baik 15 orang $(68,2 \%)$

\section{Analisa Biivariat}

Tabel 4. Pengaruh Pelatihan Berprilaku

Caring terhadap Kemampuan Caring

Mahasiswa Praktek Profesi Fakultas

Keperawatan Unand di RSUP Dr.M Djamil Padang Desember 2012

\section{Pembahasan}

\section{A. Kemampuan Perilaku Caring Mahasiswa Profesi Fakultas Keperawatan Unand}

Berdasarkan dari hasil penelitian pada tabel 2 dan tabel 3 terlihat dari 22 responden lebih dari separuh yaitu 13 orang $(59,1 \%)$ memiliki kemampuan caring cukup sebelum diberi pelatihan dan masih terdapat 6 orang $(27,3 \%)$ memiliki kemampuan kurang. Sedangkan setelah pelatihan kemampuan mahasiswa dalam berprilaku caring semua memiliki

p kemampuan baik dan sangat baik.

\begin{tabular}{|c|c|c|c|c|c|c|}
\hline \multirow{2}{*}{$\begin{array}{l}\mathbf{N} \\
\mathbf{o}\end{array}$} & \multirow{2}{*}{$\begin{array}{c}\text { Kemampuan } \\
\text { caring } \\
\text { Mahasiswa }\end{array}$} & \multicolumn{2}{|c|}{ sebelum } & \multicolumn{2}{|c|}{ Sesudah } & \multirow[b]{2}{*}{$\mathbf{p}$} \\
\hline & & Mean & $\begin{array}{c}\text { Standar } \\
\text { deviasi }\end{array}$ & $\begin{array}{c}\text { Mea } \\
\mathbf{n}\end{array}$ & $\begin{array}{c}\text { Standa } \\
\mathbf{r} \\
\text { deviasi }\end{array}$ & \\
\hline 1 & Mendengar klien & 2,13 & 0.47 & 3,68 & 0,48 & 0,000 \\
\hline 2 & $\begin{array}{l}\text { Memberi rasa } \\
\text { aman \& nyaman }\end{array}$ & 1,77 & 0,43 & 3,36 & 0,66 & 0,000 \\
\hline 3 & Memberi sentuhan & 1,81 & 0,67 & 3,72 & 0,46 & $\overline{0,000}$ \\
\hline 4 & $\begin{array}{l}\text { Membina } \\
\text { hubungan saling } \\
\text { percaya }\end{array}$ & 1,86 & 0,56 & 3,45 & 0,67 & 0,000 \\
\hline 5 & Tanggung jawab & 1,96 & 0,65 & 3,91 & 0,29 & 0,000 \\
\hline 6 & $\begin{array}{l}\text { Pemberian } \\
\text { informasi }\end{array}$ & 1,77 & 0,53 & 3,36 & 0,65 & 0,000 \\
\hline 7 & $\begin{array}{l}\text { Sensitive } \\
\text { terhadap klien }\end{array}$ & 1,86 & 0,56 & 3,36 & 0,65 & 0,000 \\
\hline 8 & $\begin{array}{l}\text { Menghormati } \\
\text { klien }\end{array}$ & 2,13 & 0,56 & 3,77 & 0,42 & 0,00 \\
\hline
\end{tabular}

Sebagai mahasiswa yang telah mendapat gelar sarjana keperawatan kondisi diatas sangat memprihatinkan mengingat bahwa mahasiswa ini pernah mendapatkan pembelajaran tentang caring selama menempuh pendidikan akademik. Hal ini menunjukkan bahwa pengetahuan caring tidak hanya sebatas konsep. Berdasarkan kurikulum profesi fakultas Keperawatan Unand 2012 bahwa salah satu indicator kelulusan mahasiswa adalah mampu berprilaku caring kepada pasien. Selain itu caring merupakan jantung bagi profesi keperawatan yang merupakan kunci dalam perawatan, dukungan emosional kepada klien,keluarga atau kerabat secara verbal maupun non verbal (Rubenfeld). Hal ini tentu perlu mendapat perhatian perawat karena melalui caring kebutuhan klien secara individu dapat di identifikasi. dan dapat memberikan kepuasan dalam memenuhi kebutuhan klien, sehingga dengan perilaku caring perawat diharapkan mutu asuhan keperawatan dapat di pertanggungjawabkan (Watson, 2005).

Nurachmah (2001) mahasiswa praktek profesi Fakultas Keperawatan unand. caring adalah inti dari serta menyatu dalam praktik keperawatan. Caring juga disebutkan sebagai sikap 
responsif dan bertanggung jawab dalam rangka memenuhi harapan klien.

Penelitian lain yang dilakukan oleh Rahayu (2001) tentang caring perawat menunjukkan hasil yang tidak jauh berbeda, terlihat proporsi perawat yang tidak caring $(51,9 \%)$ dan perawat yang caring $(48,1 \%)$.

Pelatihan yang diberikan dapat memperbaiki penampilan/kemampuan individu dalam melakukan suatu tindakan sehingga bisa meningkatkan produktivitas (fandi,1998; Marzuki,1992). Hasil penelitian juga menunjukkan setelah pelatihan dari 8 perilaku caring 20 orang mahasiswa menunjukkan rasa tanggung jawab,17 orang menunjukkan rasa menghormati klien, 16 orang memberikan sentuhan, 15 orang yang mendengarkan klien sepenuh hati dan 12 orang sangat baik membina hubungan saling percaya serta masing-masing 10 orang yang mampu menampilkan prilaku sangat baik pada memberikan informasi,sensitive dan rasa aman nyaman pada klien. Mahasiswa menunjukkan rasa tanggung jawab yang tinggi menurut responden hal ini disebabkan tanggung jawab yang dilakukan selama di RS juga merupakan poin penting dalam pencapain kompetensi kelulusan dalam profesi. Hal ini perlu juga disadari keadaan sakit membuat klien tergantung kepada perawat untuk melakukan perawatan selama di Rumah sakit..

Berdasarkan pengertian asuhan keperawatan (Depkes RI, 1999) bahwa asuhan keperawatan adalah bantuan yang diberikan kepada klien karena adanya kelemahan fisik dan mental, keterbatasan pengetahuan serta kurangnya kemauan untuk menuju kepada kemampuan melakukan kegiatan hidup sehari-hari. Maka hasil penelitian ini belum mencerminkan bahwa perawat telah melakukan asuhan keperawatan secara komprehensif terutama dalam hal perawat memberikan rasa nyaman.

Perilaku caring mahasiswa menjadi sangat baik juga dapat ditentukan oleh pengalam berinteraksi dengan pasien \& keluarga hal ini terbukti bahwa mahasiswa yang berasal akademi perawatan dan sudah memiliki pengalaman kerja semua menunjukan penampilan caring sangat baik dibandingkan dari lulusan SLTA.

\section{B. Pengaruh Pelatihan Prilaku Caring terhadap kemampuan Caring Mahasiswa Praktek profesi Fakultas Keperawatan Unand}

Berdasarkan tabel 4 didapatkan bahwa terdapat pengaruh pelatihan Caring terhadap kemampuan caring mahasiswa dengan ditunjukkan nilai $\mathrm{p}=0,000$. Dengan peningkatan nilaimean terbesar pada poin tanggung jawab.

Pelatihan yang diberikan dapat memperbaiki penampilan/kemampuan individu dalam melakukan suatu tindakan sehingga bisa meningkatkan produktivitas (fandi,1998; Marzuki,1992). Hasil penelitian juga menunjukkan setelah pelatihan dari 8 perilaku caring 20 orang mahasiswa menunjukkan rasa tanggung jawab,17 orang menunjukkan rasa menghormati klien, 16 orang memberikan sentuhan, 15 orang yang mendengarkan klien sepenuh hati dan 12 orang sangat baik membina hubungan saling percaya serta masing-masing 10 orang yang mampu menampilkan prilaku sangat baik pada memberikan informasi,sensitive dan rasa aman nyaman pada klien. Mahasiswa

menunjukkan rasa tanggung jawab yang tinggi menurut responden hal ini disebabkan tanggung jawab yang dilakukan selama di RS juga merupakan poin penting dalam pencapain kompetensi kelulusan dalam profesi. Hal ini perlu juga disadari keadaan sakit membuat klien tergantung kepada perawat untuk melakukan perawatan selama di Rumah sakit..

Berdasarkan pengertian asuhan keperawatan (Depkes RI, 1999) bahwa asuhan keperawatan adalah bantuan yang diberikan kepada klien karena adanya kelemahan fisik dan mental, keterbatasan pengetahuan serta kurangnya kemauan untuk menuju kepada 
kemampuan melakukan kegiatan hidup seharihari. Maka hasil penelitian ini belum mencerminkan bahwa perawat telah melakukan asuhan keperawatan secara komprehensif terutama dalam hal perawat memberikan rasa nyaman.

Perilaku caring mahasiswa menjadi sangat baik juga dapat ditentukan oleh pengalam berinteraksi dengan pasien \& keluarga hal ini terbukti bahwa mahasiswa yang berasal akademi perawatan dan sudah memiliki pengalaman kerja semua menunjukan penampilan caring sangat baik dibandingkan dari lulusan SLTA

\section{KESIMPULAN DAN SARAN Kesimpulan}

Pelatihan berprilaku caring yang diberikan dapat meningkatkan kemampuan mahasiswa praktek profesi Fakultas Keperawan Unand di RSUP Dr.M.Djamil Padang.

Saran

1. Menggunakan pendekatan pelatihan caring dalam kelompok kecil lebih bisa meningkatkan kemampuan psikomotor mahasiswa di lahan praktek. Dan dapat digunakan oleh bagian profesi sebagai sarat kelulusan utama

2. Untuk Rumah sakit agar menyediakan pelatihan caring sebagai bentuk penyegaran pada perawat di ruangan sehingga mutu pelayanan dapat dijaga.

\section{DAFTAR PUSTAKA}

Anjaswarni, T. (2002). Analisis Tingkat Kepuasan Klien Terhadap Perilaku Caring Perawat Di Rumah Sakit Umum Daerah Dr. Saiful Anwar Malang Tahun 2002. Tesis. FIK-UI. Diakses tanggal 10 Desember 2010, dari http://www.digilib.ui.ac.id/opac/themes/libri2 /detail.jsp?id=70768\&lokasi=lokal

Arikunto. (2002). Prosedur Penelitian Suatu Pendekatan Praktek. Jakarta : PT. Rineka Cipta
Asmadi,2008.Konsep dasar keperawatan.

Jakarta : EGC

Dahlan, M.S. (2008). Statistik Untuk

Kedokteran dan Kesehatan.

(Edisi 3). Jakarta : Salemba Medika

Depkes RI. (2002). Standar Tenaga

Keperawatan Di Rumah Sakit. Diakses tanggal 24 Desember 2010, dari http://perpustakaan.depkes.go.id/cgibin/koha/opacdetail.pl?biblionumber=1 694\&shelfbrowse itemnumber $=3111$

Henderson, Amanda. (2007). 'Caring for' behaviours that indicate to patients that nurses 'care about' them. Diakses tanggal 21 Februari 2011 dari www.ncbi.nlm.nih.gov/pubmed/17877561

Ismar, A. (2002). Perilaku caring perawat dan hubungannya dengan kepuasan klien di instalasi rawat inap bedah dewasa Rumah Sakit dokter Mohammad Hoesin. Jakarta. FIKUI

Marzuki, M. Saleh.(1992). Strategi dan Model Pelatihan. Malang:IKIPMalang.

Moekijat. (1990). Evaluasi Pelatihan Dalam Rangka Meningkatkan Produktivitas Perusahaan. Bandung: Penerbit Mandar Maju.

Moekijat. (1990). Pengembangan dan Motivasi. Bandung: Pionir Jaya.

Morrison, P. \& Burnard P. (2009). Caring and Communicating : The Interpersonel Relationship in Nursing (widyawati \& Eni M, trans). (2 ${ }^{\text {nd }}$ edition). Jakarta : EGC

Notoatmojo, S. (2005). Metodologi penelitian kesehatan. Edisi Revisi. Jakarta: Rineka Cipta.

Notoatmojo, S. (2007). Promosi kesehatan dan ilmu perilaku. Jakarta: Rineka Cipta

Potter, Patricia A, Anne G. Perry. 2009. Fundamental Of Nursing edisi 7. Jakarta: Penerbit Salemba Medika.

Sudjana, Djudju. (2004). Pendidikan Nonformal: Wawasan, Sejarah Perkembangan, Falsafah dan Teori 
Pendukung, serta Azas. Bandung:

Falah Productio

Taylor,Carol.lilis,carol dan lemone,priscilla 1997,Fundamentals of Nursing 3nd ed,phidelphia:Lippincott

Tjiptono, F dan Diana, A.

(1998). Total Quality

Management. Yogyakarta: Andi offset.

Vance, T. (2007). Caring and the professional practice of nursing. Diakses pada tanggal 21 april 2010. dari http://www.proguest.com/pqdweb.

Watson, J. (2003). Caring Science as Sacred Science. Philadelphia : FA Davis Company.

Watson, J. (2005). Assesing and measuring caring in nursing and health sciences : FA Davis Company

Yoder, D.(1962). Personel Principles and Policies. Second Edition Prentice Hall Inc: Maruzen Company Ltd. 